\title{
Evaluating High-Dose Rivastigmine Patch in Severe Alzheimer's Disease: Analyses with Concomitant Memantine Usage as a Factor
}

*George T. Grossberg ${ }^{1}$, Martin R. Farlow ${ }^{2}$, Xiangyi Meng ${ }^{3}$ and Drew M. Velting ${ }^{3}$

${ }^{1}$ Department of Neurology and Psychiatry, St Louis University School of Medicine, St Louis, MO, USA;

${ }^{2}$ Department of Neurology, Indiana University School of Medicine, Indianapolis, IN, USA;

${ }^{3}$ Novartis Pharmaceuticals Corporation, East Hanover, NJ, USA

\section{*Corresponding author:}

George T. Grossberg

Department of Neurology and Psychiatry

St Louis University School of Medicine

1438 South Grand Boulevard

St Louis, MO 63104, USA

Tel: +1 3149774825

Fax: +13149774876

Email: grossbgt@slu.edu; grossbgt@aol.com

Word count: 3854, excluding figures and tables

Tables: 2

Figures: 2

Short title: High-Dose Rivastigmine Patch \pm Memantine

This is the author's manuscript of the article published in final edited form as:

Grossberg, G., Farlow, M., Meng, X., \& Velting, D. (2015). Evaluating High-Dose Rivastigmine Patch in Severe Alzheimer's Disease: Analyses with Concomitant Memantine Usage as a Factor. Current Alzheimer Research, 12(1), 53-60. http://doi.org/10.2174/1567205011666141218122835 


\section{Abstract}

Background: ACTION, a 24-week, prospective, randomized, parallel-group, double-blind study in patients with severe Alzheimer's disease (AD), demonstrated significant efficacy of $13.3 \mathrm{mg} / 24 \mathrm{~h}$ versus $4.6 \mathrm{mg} / 24 \mathrm{~h}$ rivastigmine patch on the Severe Impairment Battery (SIB) and Alzheimer's Disease Cooperative StudyActivities of Daily Living scale-Severe Impairment Version (ADCS-ADL-SIV). Overall, 61\% of the study population received $\geq 1$ dose of concomitant memantine, regardless of dose or duration. This retrospective analysis investigated effects of concomitant memantine on the efficacy, safety and tolerability of $13.3 \mathrm{mg} / 24 \mathrm{~h}$ versus $4.6 \mathrm{mg} / 24 \mathrm{~h}$ rivastigmine patch.

Methods: Patients were stratified according to whether or not they received at least one dose of concomitant memantine during the double-blind phase. Changes from baseline on the SIB and ADCS-ADL-SIV were compared using analysis of covariance (ANCOVA) with treatment, pooled center, memantine usage and treatment-by-memantine as factors, and baseline as a covariate. Safety and tolerability were assessed.

Results: Memantine-treated patients were younger than those not receiving memantine (mean 75.9 and 78.8 years, respectively), with a lower screening Mini-Mental State Examination (8.6 and 9.2, respectively). ANCOVA confirmed there was no significant interaction ( $\mathrm{p}>0.1$ ) between study treatment and memantine use on the SIB or ADCS-ADL-SIV. The incidence of adverse events was: $71.4 \%, 13.3 \mathrm{mg} / 24 \mathrm{~h}$ patch with memantine; 79.7\%, $13.3 \mathrm{mg} / 24 \mathrm{~h}$ patch alone; 74.7\%, $4.6 \mathrm{mg} / 24 \mathrm{~h}$ patch with memantine; and 71.1\%, 4.6 mg/24 $\mathrm{h}$ patch alone.

Conclusions: These data suggest benefit of $13.3 \mathrm{mg} / 24 \mathrm{~h}$ versus $4.6 \mathrm{mg} / 24 \mathrm{~h}$ rivastigmine patch, regardless of concomitant memantine use. The incidence of adverse events with high-dose patch was similar in memantinetreated patients and those not receiving memantine.

Key words: ACTION study, high-dose, memantine, rivastigmine; severe Alzheimer's disease; transdermal patch 


\section{Introduction}

Three cholinesterase inhibitors (ChEIs), rivastigmine, donepezil and galantamine, are approved in the USA for the treatment of mild-to-moderate Alzheimer's disease (AD) [1-4]. All three are available in oral formulations $[1,3,4]$; rivastigmine is the only ChEI also approved for transdermal delivery, via a patch [2]. As well as mildto-moderate disease stages, rivastigmine transdermal patch is indicated for severe AD [2]. Oral donepezil is also indicated for moderate-to-severe $\mathrm{AD}$ [3], along with the $N$-methyl-D-aspartate (NMDA) receptor antagonist, memantine [5].

Based on memantine's alternative mechanism of action, there is a rationale for considering memantine as an add-on therapy to ChEIs in patients with moderate-to-severe AD. However, despite some positive studies in patients with moderate-to-severe $\mathrm{AD}$, the benefits of combination therapy have yet to be robustly demonstrated [6]. Post-hoc meta-analyses of data from two 24-week, randomized, double-blind, placebo-controlled trials [7, 8] reported that combination therapy with donepezil (10 mg/day) and memantine (20 mg/day) was associated with enhanced efficacy, without marked impact on safety and tolerability, compared with donepezil alone, in patients with moderate or moderate-to-severe AD [9]. However, a 52-week, double-blind, placebo-controlled study reported no significant benefit of adding memantine (20 mg/day) to donepezil (10 mg/day) [10]. Furthermore, concomitant memantine (up to $20 \mathrm{mg} /$ day) use was not found to have any impact on the efficacy of high-dose $23 \mathrm{mg} /$ day versus $10 \mathrm{mg} /$ day donepezil in a post-hoc analysis of a clinical study in patients with moderate-to-severe $\mathrm{AD}$ [11]. In this study, the incidence of treatment-emergent adverse events (AEs) was higher with $23 \mathrm{mg} /$ day donepezil with memantine (80.7\%) compared with $23 \mathrm{mg} /$ day donepezil without memantine (69.7\%) [11].

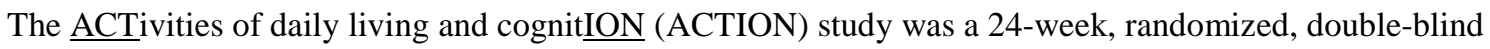
comparison of $13.3 \mathrm{mg} / 24 \mathrm{~h}$ and $4.6 \mathrm{mg} / 24 \mathrm{~h}$ rivastigmine patch in patients with severe AD [12, 13]. In this study, the high-dose (13.3 mg/24 h) rivastigmine patch showed significantly superior efficacy compared with the low-dose (4.6 mg/24 h) rivastigmine patch on both co-primary endpoints, the Severe Impairment Battery (SIB) and the Alzheimer's Disease Cooperative Study-Activities of Daily Living scale-Severe Impairment Version (ADCS-ADL-SIV) [13]. Given the advanced disease stage of the study population, patients were permitted to use concomitant memantine during the double-blind phase, provided they had been receiving a stable dose for at least 3 months prior to the screening visit [13]. The objective of the current post-hoc analysis of the ACTION study was to investigate the efficacy, safety and tolerability of the high-dose $13.3 \mathrm{mg} / 24 \mathrm{~h}$ versus the low-dose $4.6 \mathrm{mg} / 24 \mathrm{~h}$ rivastigmine patch in patients with severe AD stratified according to their use of concomitant memantine (up to $20 \mathrm{mg} /$ day) during double-blind treatment.

\section{Material and Methods}

Study Design and Patients

This was a retrospective post-hoc analysis of the 24-week, prospective, randomized, double-blind, doubledummy, multicenter, US-based, ACTION study (ClinicalTrials.gov Identifier: NCT00948766) [12, 13]. 
Detailed methodology of the ACTION study has been published previously [12, 13]. Briefly, patients were male or female, aged $\geq 50$ years, with probable AD (original 1984 National Institute of Neurological and Communicative Disorders and Stroke and AD and Related Disorders Association criteria) [14], and a MiniMental State Examination (MMSE) [15] score of 3-12, inclusive. Patients were excluded if they had received ChEIs and/or other approved treatments for AD during the previous 2 weeks, with the exception of stable memantine if taken for at least 3 months prior to screening. Eligible patients were randomized in a 1:1 ratio to receive $13.3 \mathrm{mg} / 24 \mathrm{~h}$ or $4.6 \mathrm{mg} / 24 \mathrm{~h}$ rivastigmine patch for 24 weeks. Co-primary outcome measures were the change from baseline at Week 24 on the SIB [16] and the ADCS-ADL-SIV [17]. Safety assessments included the incidence of AEs, serious AEs (SAEs), and discontinuations due to AEs or SAEs.

The ACTION study was conducted in accordance with Good Clinical Practice and the ethical principles of the Declaration of Helsinki. All patients, or their legally authorized representative, provided written informed consent prior to participating.

\section{Statistical Analysis}

In the current analysis, patients randomized to $13.3 \mathrm{mg} / 24 \mathrm{~h}$ or $4.6 \mathrm{mg} / 24 \mathrm{~h}$ rivastigmine patch were stratified according to whether or not they received at least one dose of concomitant memantine (up to $20 \mathrm{mg} /$ day) during the double-blind phase.

The least-squares mean (LSM) change from baseline at Weeks 8, 16 and 24 (Week 24 being the primary endpoint) on the SIB and ADCS-ADL-SIV were estimated for each subgroup (13.3 mg/24 h rivastigmine patch with memantine, $4.6 \mathrm{mg} / 24 \mathrm{~h}$ rivastigmine patch with memantine, $13.3 \mathrm{mg} / 24 \mathrm{~h}$ rivastigmine patch without memantine, and $4.6 \mathrm{mg} / 24 \mathrm{~h}$ rivastigmine patch without memantine). The efficacy of $13.3 \mathrm{mg} / 24 \mathrm{~h}$ versus 4.6 $\mathrm{mg} / 24 \mathrm{~h}$ rivastigmine patch in patients who received concomitant memantine, and $13.3 \mathrm{mg} / 24 \mathrm{~h}$ versus 4.6 $\mathrm{mg} / 24 \mathrm{~h}$ rivastigmine patch in patients not treated with memantine was compared using analysis of covariance (ANCOVA) with treatment, pooled center, memantine usage and treatment-by-memantine as factors, and the respective baseline as a covariate. To address imbalance in between-group patient demographics and characteristics additional between-group comparisons using the same model were performed for completeness.

Efficacy analyses were based on the Modified Full Analysis Set (MFAS), which included all randomized patients who received at least one dose of study medication and had at least one post-baseline measurement, with missing data imputed using the Last Observation Carried Forward (LOCF) approach.

Sensitivity analyses for the SIB and ADCS-ADL-SIV were conducted using a Mixed-Effect Model Repeated Measure (MMRM) and pattern mixture models. MMRM analyses were based on a repeated measures ANCOVA model with treatment, pooled center, visit, memantine usage, memantine usage-by-treatment, treatment-by-visit, visit-by-memantine usage and visit-by-memantine usage-by-treatment as factors, and the respective baseline total score as a covariate, assuming an unstructured within-subject covariance matrix. Pattern mixture model analyses were based on a repeated measures ANCOVA model with treatment, visit, pooled center, memantine usage, dropout, memantine usage-by-treatment, treatment-by-visit, visit-by-memantine usage, dropout-by-memantine usage, treatment-by-dropout, visit-by-memantine usage-by-treatment and 
dropout-by-memantine usage-by-treatment as factors, and the respective baseline total score as a covariate, assuming an unstructured within-subject covariance matrix.

Safety evaluations included the incidence of AEs and SAEs in each subgroup. The safety set included all patients who received at least one dose of study medication and had at least one safety assessment post-baseline.

\section{Results}

\section{Participants}

Of 716 patients randomized to $13.3 \mathrm{mg} / 24 \mathrm{~h}$ or $4.6 \mathrm{mg} / 24 \mathrm{~h}$ rivastigmine patch, 435 (60.8\%; $13.3 \mathrm{mg} / 24 \mathrm{~h}$ rivastigmine patch, $\mathrm{N}=217 ; 4.6 \mathrm{mg} / 24 \mathrm{~h}$ rivastigmine patch, $\mathrm{N}=218$ ) received concomitant memantine, regardless of dose or treatment duration.

The study was completed by a similar proportion of patients who received $13.3 \mathrm{mg} / 24 \mathrm{~h}$ rivastigmine patch and memantine (66.8\%), $4.6 \mathrm{mg} / 24 \mathrm{~h}$ rivastigmine patch and memantine (65.1\%), $13.3 \mathrm{mg} / 24 \mathrm{~h}$ rivastigmine patch without memantine (60.4\%) and $4.6 \mathrm{mg} / 24 \mathrm{~h}$ rivastigmine patch without memantine (64.8\%). In all subgroups, AEs (13.3 mg/24 h rivastigmine patch and memantine, $18.0 \%$; $4.6 \mathrm{mg} / 24 \mathrm{~h}$ rivastigmine patch and memantine, $12.4 \% ; 13.3 \mathrm{mg} / 24 \mathrm{~h}$ rivastigmine patch without memantine, $24.5 \%$; and $4.6 \mathrm{mg} / 24 \mathrm{~h}$ rivastigmine patch without memantine, $16.9 \%$ ) and withdrawal of consent $(7.4 \%, 12.4 \%, 7.9 \%$ and $13.4 \%$, respectively) were the primary reasons for discontinuation.

Baseline demographics and characteristics were generally comparable, with the exception that memantinetreated patients tended to be slightly younger, with a longer time since AD diagnosis compared with those who did not receive memantine (Table $\mathbf{1}$ ).

Table 1. Patient demographics and background characteristics by treatment group and concomitant memantine use (randomized set).

\begin{tabular}{|c|c|c|c|c|c|c|}
\hline & \multicolumn{3}{|c|}{$\begin{array}{c}\text { Patients with } \\
\text { concomitant memantine use }\end{array}$} & \multicolumn{3}{|c|}{$\begin{array}{c}\text { Patients without } \\
\text { concomitant memantine use }\end{array}$} \\
\hline & $\begin{array}{c}13.3 \mathrm{mg} / 24 \mathrm{~h} \\
\text { rivastigmine } \\
\text { patch } \\
\mathrm{N}=217\end{array}$ & $\begin{array}{c}4.6 \mathrm{mg} / 24 \mathrm{~h} \\
\text { rivastigmine } \\
\text { patch } \\
\mathrm{N}=218\end{array}$ & $\mathrm{~N}=435$ & \begin{tabular}{|c|}
$13.3 \mathrm{mg} / 24 \mathrm{~h}$ \\
rivastigmine \\
patch \\
$\mathrm{N}=139$
\end{tabular} & \begin{tabular}{|c|}
$4.6 \mathrm{mg} / 24 \mathrm{~h}$ \\
rivastigmine \\
patch \\
$\mathrm{N}=142$
\end{tabular} & $\mathrm{~N}=\mathbf{2 8 1}$ \\
\hline Mean (SD) age, years & $76.3(8.6)$ & $75.5(9.0)$ & $75.9(8.8)$ & 79.6 (8.5) & $78.0(9.8)$ & $78.8(9.2)$ \\
\hline Gender, \% female & 62.7 & 64.7 & 63.7 & 65.5 & 65.5 & 65.5 \\
\hline Race, \% & & & & & & \\
\hline Caucasian & 88.5 & 89.4 & 89.0 & 82.0 & 87.3 & 84.7 \\
\hline Black & 8.3 & 5.0 & 6.7 & 7.2 & 5.6 & 6.4 \\
\hline Other & 3.2 & 5.5 & 4.4 & 10.8 & 7.0 & 8.9 \\
\hline Mean (SD) weight, kg & $70.4(14.8)$ & $70.5(15.3)^{*}$ & $70.4(15.0)^{\dagger}$ & $67.1(14.7)^{\ddagger}$ & $67.9(16.6)$ & $67.5(15.7)^{\S}$ \\
\hline
\end{tabular}




\begin{tabular}{|c|c|c|c|c|c|c|}
\hline MMSE at screening & & & & & & \\
\hline Mean (SD) & $8.7(2.8)$ & $8.6(3.0)$ & $8.6(2.9)$ & $9.1(2.9)$ & $9.2(2.9)$ & $9.2(2.9)$ \\
\hline Range & $3.0-13.0$ & $3.0-19.0$ & $3.0-19.0$ & $3.0-12.0$ & $3.0-12.0$ & $3.0-12.0$ \\
\hline $\begin{array}{l}\text { Mean (SD) baseline } \\
\text { SIB score }\end{array}$ & $66.4(22.3)^{\pi}$ & $65.8(23.1)^{\pi}$ & $66.1(22.7)^{\mid}$ & $73.2(19.6)^{* *}$ & $71.3(22.2)$ & $72.2(20.9)^{\dagger \dagger}$ \\
\hline $\begin{array}{l}\text { Mean (SD) baseline } \\
\text { ADCS-ADL-SIV score }\end{array}$ & $29.9(11.0)^{\ddagger \ddagger}$ & $28.8(11.3)^{\S \S}$ & $29.4(11.1)^{\text {ศโ }}$ & $29.4(11.6)^{* *}$ & $29.4(12.9)^{\ddagger}$ & $29.4(12.2)^{\| \prime}$ \\
\hline $\begin{array}{l}\text { Mean (SD) years since } \\
\text { diagnosis of AD }\end{array}$ & $4.6(2.6)$ & $4.4(2.6)$ & $4.5(2.6)$ & $3.6(2.8)$ & $3.4(2.6)$ & $3.5(2.7)$ \\
\hline $\begin{array}{l}\text { Mean (SD) years since } \\
\text { diagnosis of severe } \\
\text { dementia }\end{array}$ & $1.3(1.9)$ & $1.4(1.8)$ & $1.3(1.8)$ & $1.1(1.9)$ & $0.9(1.2)^{* * *}$ & $1.0(1.6)^{\S}$ \\
\hline Living situation, \% & & & & & & \\
\hline Home & 89.4 & 88.1 & 88.7 & 92.1 & 88.0 & 90.0 \\
\hline $\begin{array}{l}\text { Assisted living } \\
\text { facility }\end{array}$ & 8.3 & 10.1 & 9.2 & 6.5 & 9.2 & 7.8 \\
\hline Other & 2.3 & 1.8 & 2.1 & 1.4 & 2.8 & 2.1 \\
\hline
\end{tabular}

AD, Alzheimer's disease; ADCS-ADL-SIV, Alzheimer's Disease Cooperative Study-Activities of Daily Living scale-Severe Impairment Version; MMSE, Mini-Mental State Examination; N, number of patients in the population; n, number of patients reporting with available data; SD, standard deviation; SIB, Severe Impairment

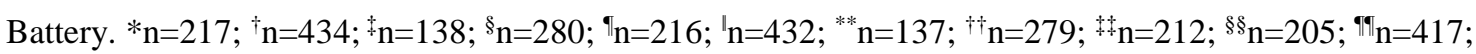
${ }^{1 "} \mathrm{n}=275 ;{ }^{* * *} \mathrm{n}=141$.

\section{Efficacy Outcomes}

Numerically less decline was observed on the SIB and ADCS-ADL-SIV with $13.3 \mathrm{mg} / 24 \mathrm{~h}$ versus $4.6 \mathrm{mg} / 24 \mathrm{~h}$ rivastigmine patch, regardless of concomitant memantine use. The high-dose $13.3 \mathrm{mg} / 24 \mathrm{~h}$ rivastigmine patch was associated with significantly greater efficacy versus the low-dose $4.6 \mathrm{mg} / 24 \mathrm{~h}$ rivastigmine patch on the SIB at Weeks 16 and 24, both in patients receiving concomitant memantine (LSM difference [95\% CI]: 3.6 [1.0, 6.3]), $\mathrm{p}=0.01$; and $3.8[1.1,6.5], \mathrm{p}=0.01$, respectively) and patients who did not receive concomitant memantine (6.9 [3.5, 10.2], $\mathrm{p}<0.0001$; and 6.6 (3.3, 10.0], p=0.0001, respectively; Fig. 1). On the ADCS-ADL-SIV, significantly less decline (LSM difference [95\% CI]: 1.4 [0.0, 2.8], p=0.04) was observed at Week 24 with 13.3 $\mathrm{mg} / 24 \mathrm{~h}$ versus $4.6 \mathrm{mg} / 24 \mathrm{~h}$ rivastigmine patch in patients who received concomitant memantine (Fig. 2).

Overall, ANCOVA analysis confirmed that there was no significant interaction ( $p>0.1$ ) between treatment and memantine use at any time point on the SIB (Week 8, p=0.95; Week 16, $\mathrm{p}=0.14$; Week 24, $\mathrm{p}=0.20$ ) or ADCSADL-SIV (Week 8, p=0.96; Week 16, p=0.68; Week 24, p=0.69). These findings were supported by the sensitivity (MMRM and pattern mixture model) analyses (SIB: $\mathrm{p}=0.15$ and $\mathrm{p}=0.53$, respectively; ADCS-ADLSIV, $\mathrm{p}=0.88$ and $\mathrm{p}=0.49$, respectively). 
Based on the observed differences at baseline between memantine-treated patients, and patients not receiving memantine, additional ANCOVA analyses were performed, which included baseline MMSE score, age and time since diagnosis of $\mathrm{AD}$ as additional covariates. In general, the findings obtained with this model were similar to those obtained with the original ANCOVA model.

\section{Safety and Tolerability}

All patients (i.e. 100\%) in the $4.6 \mathrm{mg} / 24 \mathrm{~h}$ rivastigmine patch group (regardless of memantine use), $84.8 \%$ of patients randomized to $13.3 \mathrm{mg} / 24 \mathrm{~h}$ rivastigmine patch who received memantine and $85.5 \%$ of patients randomized to $13.3 \mathrm{mg} / 24 \mathrm{~h}$ rivastigmine patch who did not receive memantine were treated with the target dose at the end of the study. The mean (standard deviation [SD]) duration of exposure to rivastigmine (in weeks) was similar in all subgroups (13.3 mg/24 h rivastigmine patch and memantine, 19.8 [8.0]; $4.6 \mathrm{mg} / 24 \mathrm{~h}$ rivastigmine patch and memantine, 20.1 [7.4]; $13.3 \mathrm{mg} / 24 \mathrm{~h}$ rivastigmine patch without memantine, 19.4 [7.8]; $4.6 \mathrm{mg} / 24 \mathrm{~h}$ rivastigmine patch without memantine, 20.0 [8.0]).

The incidence of AEs was similar in all subgroups (Table 2). The most common AEs reported by patients who received $13.3 \mathrm{mg} / 24 \mathrm{~h}$ rivastigmine patch and memantine were application site erythema (13.4\%), agitation (12.9\%), application site dermatitis (9.2\%) and fall (9.2\%); in those who received $13.3 \mathrm{mg} / 24 \mathrm{~h}$ rivastigmine patch without memantine, AEs were most commonly urinary tract infection (13.0\%), application site erythema (13.0\%) and agitation (9.4\%). In patients randomized to $4.6 \mathrm{mg} / 24 \mathrm{~h}$ rivastigmine patch who received memantine, the most common AEs were agitation (13.8\%), application site erythema (12.9\%) and urinary tract infection (8.8\%); and in those who received $4.6 \mathrm{mg} / 24 \mathrm{~h}$ rivastigmine patch without memantine, AEs were most commonly agitation (14.8\%), urinary tract infection (10.6\%) and application site dermatitis (10.6\%).

The incidence of SAEs was similar in all subgroups (Table 2). In both the $13.3 \mathrm{mg} / 24 \mathrm{~h}$ and $4.6 \mathrm{mg} / 24 \mathrm{~h}$ patch groups, the proportion of patients who discontinued due to AEs or SAEs was slightly higher in patients who did not receive concomitant memantine compared with those who received memantine. 
Table 2. Discontinuation due to AEs and SAEs, and most frequent AEs* by treatment group and concomitant memantine use (safety set).

\begin{tabular}{|c|c|c|c|c|c|c|}
\hline & \multicolumn{3}{|c|}{$\begin{array}{l}\text { Patients with } \\
\text { concomitant memantine use }\end{array}$} & \multicolumn{3}{|c|}{$\begin{array}{c}\text { Patients without concomitant } \\
\text { memantine use }\end{array}$} \\
\hline & \begin{tabular}{|c}
$13.3 \mathrm{mg} / 24 \mathrm{~h}$ \\
rivastigmine \\
patch \\
$\mathrm{N}=217$ \\
$\mathrm{n}(\%)$
\end{tabular} & $\begin{array}{c}4.6 \mathrm{mg} / 24 \mathrm{~h} \\
\text { rivastigmine } \\
\text { patch } \\
\mathrm{N}=217 \\
\mathrm{n}(\%)\end{array}$ & $\begin{array}{l}\text { Overall } \\
\text { N=434 } \\
\text { n (\%) }\end{array}$ & \begin{tabular}{|c}
$13.3 \mathrm{mg} / 24 \mathrm{~h}$ \\
rivastigmine \\
patch \\
$\mathrm{N}=138$ \\
$\mathrm{n}(\%)$
\end{tabular} & $\begin{array}{c}4.6 \mathrm{mg} / 24 \mathrm{~h} \\
\text { rivastigmine } \\
\text { patch } \\
\mathrm{N}=142 \\
\mathrm{n}(\%)\end{array}$ & $\begin{array}{l}\text { Overall } \\
\text { N=280 } \\
\text { n (\%) }\end{array}$ \\
\hline Any AE & 155 (71.4) & $162(74.7)$ & 317 (73.0) & 110 (79.7) & $101(71.1)$ & $211(75.4)$ \\
\hline Any SAE & 32 (14.7) & $26(12.0)$ & 58 (13.4) & $21(15.2)$ & $23(16.2)$ & $44(15.7)$ \\
\hline $\begin{array}{l}\text { Discontinuation } \\
\text { due to } \mathrm{AE}\end{array}$ & $40(18.4)$ & $28(12.9)$ & $68(15.7)$ & 33 (23.9) & $24(16.9)$ & $57(20.4)$ \\
\hline $\begin{array}{l}\text { Discontinuation } \\
\text { due to SAE }\end{array}$ & $16(7.4)$ & $6(2.8)$ & $22(5.1)$ & $13(9.4)$ & $10(7.0)$ & $23(8.2)$ \\
\hline \multicolumn{7}{|c|}{ Most common AEs (preferred term) } \\
\hline $\begin{array}{l}\text { Application site } \\
\text { erythema }\end{array}$ & $29(13.4)$ & 28 (12.9) & $57(13.1)$ & $18(13.0)$ & $14(9.9)$ & $32(11.4)$ \\
\hline Agitation & 28 (12.9) & 30 (13.8) & 58 (13.4) & $13(9.4)$ & $21(14.8)$ & 34 (12.1) \\
\hline $\begin{array}{l}\text { Application site } \\
\text { dermatitis }\end{array}$ & $20(9.2)$ & $18(8.3)$ & $38(8.8)$ & $7(5.1)$ & $15(10.6)$ & 22 (7.9) \\
\hline Fall & $20(9.2)$ & $16(7.4)$ & $36(8.3)$ & $7(5.1)$ & $5(3.5)$ & $12(4.3)$ \\
\hline Insomnia & $16(7.4)$ & $10(4.6)$ & $26(6.0)$ & $9(6.5)$ & $5(3.5)$ & $14(5.0)$ \\
\hline Vomiting & $16(7.4)$ & $6(2.8)$ & $22(5.1)$ & $9(6.5)$ & $3(2.1)$ & $12(4.3)$ \\
\hline Nausea & 15 (6.9) & $5(2.3)$ & $20(4.6)$ & $7(5.1)$ & $5(3.5)$ & $12(4.3)$ \\
\hline Weight decreased & $15(6.9)$ & $8(3.7)$ & $23(5.3)$ & $8(5.8)$ & $3(2.1)$ & $11(3.9)$ \\
\hline Diarrhea & $12(5.5)$ & $9(4.1)$ & $21(4.8)$ & $11(8.0)$ & $10(7.0)$ & $21(7.5)$ \\
\hline Depression & $11(5.1)$ & $9(4.1)$ & $20(4.6)$ & $6(4.3)$ & $6(4.2)$ & $12(4.3)$ \\
\hline $\begin{array}{l}\text { Urinary tract } \\
\text { infection }\end{array}$ & $11(5.1)$ & $19(8.8)$ & 30 (6.9) & $18(13.0)$ & $15(10.6)$ & 33 (11.8) \\
\hline Anxiety & $10(4.6)$ & $11(5.1)$ & $21(4.8)$ & $6(4.3)$ & $5(3.5)$ & 11 (3.9) \\
\hline $\begin{array}{l}\text { Decreased } \\
\text { appetite }\end{array}$ & $10(4.6)$ & $3(1.4)$ & $13(3.0)$ & $7(5.1)$ & $2(1.4)$ & $9(3.2)$ \\
\hline Edema peripheral & $5(2.3)$ & $12(5.5)$ & 17 (3.9) & $3(2.2)$ & $0(0.0)$ & $3(1.1)$ \\
\hline Somnolence & $5(2.3)$ & $5(2.3)$ & $10(2.3)$ & $7(5.1)$ & $4(2.8)$ & $11(3.9)$ \\
\hline
\end{tabular}


AE, adverse event; $N$, number of patients in the population; $n$, number of patients reporting AE; SAE, serious adverse event. *Only AEs occurring in $\geq 5 \%$ of patients in the $13.3 \mathrm{mg} / 24 \mathrm{~h}$ or $4.6 \mathrm{mg} / 24 \mathrm{~h}$ rivastigmine patch group are shown. A patient with multiple occurrences of an AE was counted only once in the AE category. AEs are presented by descending frequency in patients randomized to $13.3 \mathrm{mg} / 24 \mathrm{~h}$ rivastigmine patch who received concomitant memantine.

\section{Discussion}

The current retrospective analysis investigated the efficacy, safety and tolerability of high-dose (13.3 mg/24 h) rivastigmine patch versus low-dose $(4.6 \mathrm{mg} / 24 \mathrm{~h})$ rivastigmine patch in patients stratified according to their use of concomitant memantine during double-blind treatment. Given the advanced disease stage of the enrolled patient population (mean MMSE score at screening, 8.8) and the indication of memantine for moderate-tosevere AD [5], it was not unexpected that $61 \%$ of this North American patient population received at least one dose of concomitant memantine during the study [13]. Based on our clinical experience, the proportion of patients in this study who received concomitant memantine is consistent with real-world clinical practice in the USA.

Administering agents with distinct mechanisms of action, such as memantine (NMDA receptor antagonist) [5] and rivastigmine (ChEI) [1, 2] in combination may be associated with differential and/or additive effects. In addition to a potential class effect, rivastigmine is unique amongst the approved ChEIs, in that it is the only one to inhibit both acetylcholinesterase and butyrylcholinesterase (donepezil and galantamine are acetylcholinesterase-selective) [18]. In addition, although widely considered to be a symptomatic treatment, studies in rodents have provided evidence for positive effects of rivastigmine on neurodegeneration in the synapse [19, 20]. These mechanistic differences may have biological implications. Given that the efficacy of rivastigmine is dose-dependent and cholinergic deficits increase with disease severity [21, 22], it seems clinically relevant to investigate the combination of memantine and high-dose rivastigmine in patients with severe AD. Studies with high-dose rivastigmine are made possible via transdermal delivery, which provides access to higher doses than can be reached with oral formulations, due to improved tolerability [23]. To our knowledge, these were the first analyses to investigate the concomitant use of $13.3 \mathrm{mg} / 24 \mathrm{~h}$ rivastigmine patch and memantine in a population with severe AD.

Supporting the primary efficacy findings from the ACTION study [13], superior efficacy was observed on the SIB with $13.3 \mathrm{mg} / 24 \mathrm{~h}$ versus $4.6 \mathrm{mg} / 24 \mathrm{~h}$ rivastigmine patch in patients who received concomitant memantine and those not receiving memantine. Significant between-group differences (13.3 mg/24 h versus $4.6 \mathrm{mg} / 24 \mathrm{~h}$ rivastigmine patch) were also observed at Week 24 on the ADCS-ADL-SIV in memantine-treated patients, and there was a numerical trend toward greater efficacy with the high-dose $13.3 \mathrm{mg} / 24 \mathrm{~h}$ rivastigmine patch in those not receiving memantine. The lack of statistical significance in the change from baseline at Week 24 on the ADCS-ADL-SIV between patients randomized to $13.3 \mathrm{mg} / 24 \mathrm{~h}$ versus $4.6 \mathrm{mg} / 24 \mathrm{~h}$ rivastigmine patch who did not receive memantine may have been due, in part, to the small sample size of this subpopulation. Overall, these analyses, based on the MFAS population with a LOCF imputation, and supportive MMRM and pattern mixture 
model analyses, demonstrated there was no significant interaction between rivastigmine patch treatment and memantine use.

With regard to safety, the current analyses suggest that, although there was a slightly higher incidence of AEs among $13.3 \mathrm{mg} / 24 \mathrm{~h}$ rivastigmine patch-treated patients who did not receive concomitant memantine compared with those who received memantine (79.7\% versus 71.4\%), the safety and tolerability profile of $13.3 \mathrm{mg} / 24 \mathrm{~h}$ rivastigmine patch was generally similar in both subpopulations.

The current post-hoc analyses were intended to be hypothesis-forming, and this should be taken into consideration when interpreting the findings. The ACTION study was not powered to detect effects of memantine use on the efficacy, safety and tolerability of $13.3 \mathrm{mg} / 24 \mathrm{~h}$ versus $4.6 \mathrm{mg} / 24 \mathrm{~h}$ rivastigmine patch. Although the current analyses suggest there are no additive effects of concomitant treatment with memantine and rivastigmine, additional analyses would be required to confirm these findings. It should be noted that patients were not randomly allocated to memantine treatment; hence there were imbalances between the subpopulations with regard to their baseline characteristics, which may also have influenced findings. However, similar findings were obtained regardless of whether baseline MMSE score, age, and time since AD diagnosis were included as covariates in the statistical model, suggesting these factors do not have a marked impact on the observed results.

The effect of concomitant memantine use on the efficacy, safety and tolerability of $9.5 \mathrm{mg} / 24 \mathrm{~h}$ rivastigmine patch in patients with mild-to-moderate $\mathrm{AD}$ has been previously investigated [24, 25]. An open-label study reported no marked differences in the safety or efficacy of combination therapy with $9.5 \mathrm{mg} / 24 \mathrm{~h}$ rivastigmine patch and memantine compared with $9.5 \mathrm{mg} / 24 \mathrm{~h}$ rivastigmine patch alone in patients with mild-to-moderate AD [24]. Furthermore, post-hoc analysis of a 25-week, randomized, open-label study reported a non-significant increase in the incidence of AEs in patients with mild-to-moderate AD treated with $9.5 \mathrm{mg} / 24 \mathrm{~h}$ rivastigmine patch plus memantine, compared with memantine alone (73.3\% versus 67.5\%) [25]. Overall, there were no significant differences in the efficacy of $9.5 \mathrm{mg} / 24 \mathrm{~h}$ rivastigmine patch between patients receiving memantine and patients not receiving memantine on the Clinical Global Impression of Change, or the MMSE; memantinetreated patients demonstrated significantly greater deterioration on the ADCS-ADL scale compared with those not receiving memantine [25]. The $9.5 \mathrm{mg} / 24 \mathrm{~h}$ rivastigmine patch was not included in the current analysis, as although used during dose titration, it was not a randomized target dose in the ACTION study. During ACTION, the first study of rivastigmine patch in patients with severe AD, $4.6 \mathrm{mg} / 24 \mathrm{~h}$ patch was selected as a low-dose active comparator to fully investigate the efficacy, safety and tolerability of the high-dose $13.3 \mathrm{mg} / 24$ $\mathrm{h}$ patch in this patient population [13]. Further, large-scale, randomized, controlled clinical studies would be required to fully investigate the effect of memantine use on the efficacy, safety and tolerability of $13.3 \mathrm{mg} / 24 \mathrm{~h}$ rivastigmine patch (and other patch doses, i.e. $9.5 \mathrm{mg} / 24 \mathrm{~h}$ ) in patients with severe AD. 


\section{Conclusion}

These data suggest high-dose $13.3 \mathrm{mg} / 24 \mathrm{~h}$ rivastigmine patch is associated with greater efficacy compared with $4.6 \mathrm{mg} / 24 \mathrm{~h}$ rivastigmine patch on cognition and the ability to perform activities of daily living in patients with severe $\mathrm{AD}$, regardless of whether or not the patient received concomitant memantine. In the USA, the high-dose $13.3 \mathrm{mg} / 24 \mathrm{~h}$ rivastigmine transdermal patch can now be considered as a treatment option across all disease stages, from mild-to-moderate to severe AD [2]. Memantine may be considered as an add-on therapy in patients with moderate-to-severe disease [26], but does not appear to affect the efficacy, safety and tolerability of ChEI treatment.

\section{Trial registration}

The ACTION study (ClinicalTrials.gov Identifier: NCT00948766) was funded by Novartis Pharmaceuticals Corporation, East Hanover, New Jersey, USA.

\section{Conflicts of Interest}

GTG has served as a consultant for Accera, Baxter Bioscience, Forest Labs, Lundbeck, Novartis, Otsuka, and Takeda; has received research support from Accera, Baxter, Elan, Forest, Janssen, NIH, Novartis, Noven, and Pfizer; and serves on a safety monitoring board for Merck. MF has served as a paid consultant for Accera, Alltech, Astellas, Avanir, Bayer, Biogen, Bristol-Myers Squibb, Eisai Medical Research, GE Healthcare, Grifols, Helicon, INC Research, Medavante, Medivation Inc., Merck and Co. Inc., Novartis, Pfizer, Prana Biotech, QR Pharma, Sanofi Aventis Groupe, Schering-Plough, Eli Lilly, Shire Pharmaceuticals, and Toyama; is a paid speaker for Eisai, Forest, Novartis, Eli Lilly and Pfizer; and receives research support from Accera, Biogen, Eisai, Eli Lilly and Co., Genentech, Navidea, Novartis Pharma, and Roche. XM and DV are full-time employees and stock holders of Novartis Pharmaceuticals Corporation, East Hanover, New Jersey, USA.

Development of this manuscript was supported by Novartis Pharmaceuticals Corporation, East Hanover, New Jersey, USA. Medical writing and editorial assistance were provided by Katy Cooke at Fishawack Communications Ltd, Oxford, UK, and this service was supported by Novartis Pharmaceuticals Corporation, East Hanover, New Jersey, USA.

\section{Acknowledgements:}

Medical writing and editorial assistance were provided by Katy Cooke at Fishawack Communications Ltd, Oxford, UK, and this service was supported by Novartis Pharmaceuticals Corporation, East Hanover, New Jersey, USA.

\section{Author contributions}


GTG and MRF were Principal Investigators of the ACTION study. XM performed the statistical analyses on which this article is based. All authors (GTG, MRF, XM, DV) contributed to the content, drafting, critical review, revision and approval of this manuscript. 
Fig. (1). Least-squares mean change from baseline to Week 24 on the SIB (MFAS-LOCF).

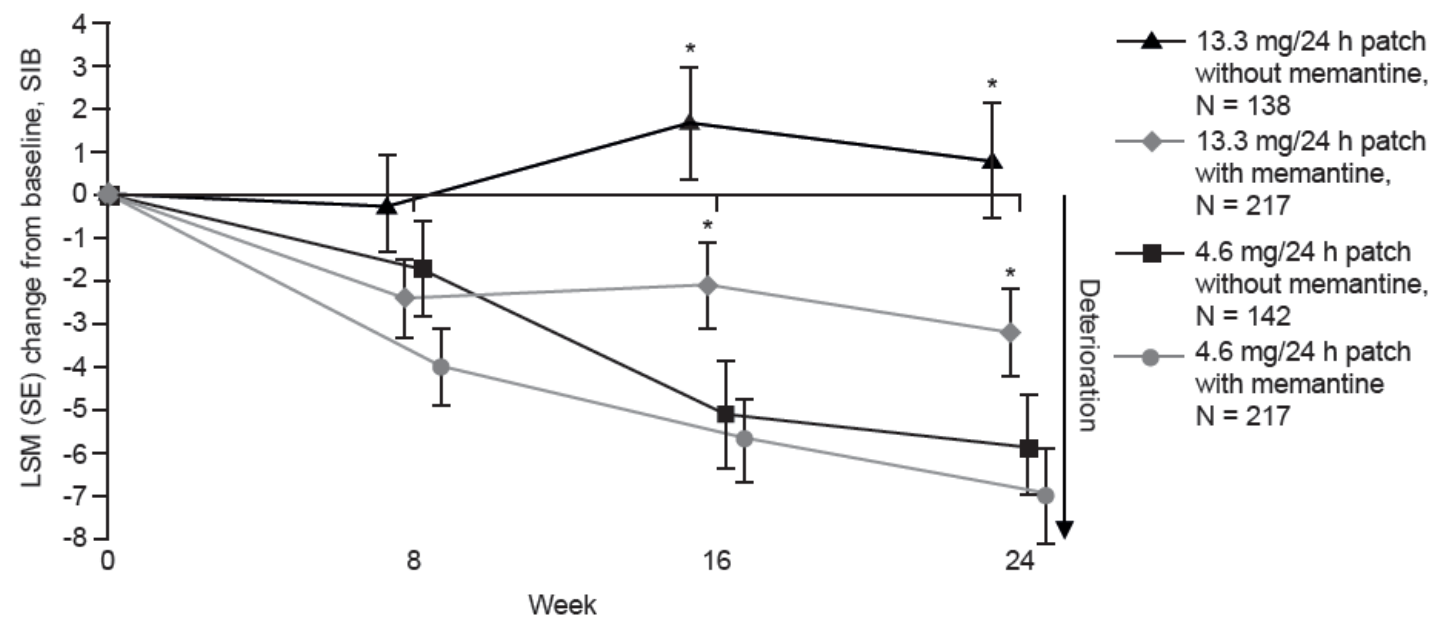

\begin{tabular}{|c|c|c|c|}
\hline \multicolumn{2}{|c|}{ Comparison } & $\begin{array}{c}\text { Point estimate } \\
\text { (+, with memantine; -, without memantine) }\end{array}$ & P-value \\
\hline $13.3 \mathrm{mg} / 24 \mathrm{~h}-$ & $13.3 \mathrm{mg} / 24 \mathrm{~h}+$ & 3.96 & 0.02 \\
\hline $13.3 \mathrm{mg} / 24 \mathrm{~h}-$ & $4.6 \mathrm{mg} / 24 \mathrm{~h} \mathrm{-}$ & 6.64 & 0.0001 \\
\hline $13.3 \mathrm{mg} / 24 \mathrm{~h}-$ & $4.6 \mathrm{mg} / 24 \mathrm{~h}+$ & 7.74 & $<0.0001$ \\
\hline $13.3 \mathrm{mg} / 24 \mathrm{~h}+$ & $4.6 \mathrm{mg} / 24 \mathrm{~h} \mathrm{-}$ & 2.68 & 0.10 \\
\hline $13.3 \mathrm{mg} / 24 \mathrm{~h}+$ & $4.6 \mathrm{mg} / 24 \mathrm{~h}+$ & 3.78 & 0.01 \\
\hline $4.6 \mathrm{mg} / 24 \mathrm{~h}-$ & $4.6 \mathrm{mg} / 24 \mathrm{~h}+$ & 1.10 & 0.50 \\
\hline
\end{tabular}

LSM, least-squares mean; MFAS-LOCF, Modified Full Analysis Set with a Last Observation Carried Forward imputation; SIB, Severe Impairment Battery; SE, standard error. Error bars represent the SE of the LSM.

${ }^{*} \mathrm{p}<0.0113 .3 \mathrm{mg} / 24 \mathrm{~h}$ versus $4.6 \mathrm{mg} / 24 \mathrm{~h}$ rivastigmine patch. $13.3 \mathrm{mg} / 24 \mathrm{~h}$ patch without memantine, $\mathrm{n}=121-$ 122; $13.3 \mathrm{mg} / 24 \mathrm{~h}$ patch with memantine, $\mathrm{n}=189-191 ; 4.6 \mathrm{mg} / 24 \mathrm{~h}$ patch without memantine, $\mathrm{n}=123-124 ; 4.6$ mg/24 h patch with memantine, $n=189-192$. Change from baseline at Weeks 8, 16 and 24 shown (data points are staggered). 
Fig. (2). Least-squares mean change from baseline to Week 24 on the ADCS-ADL-SIV (MFAS-LOCF).

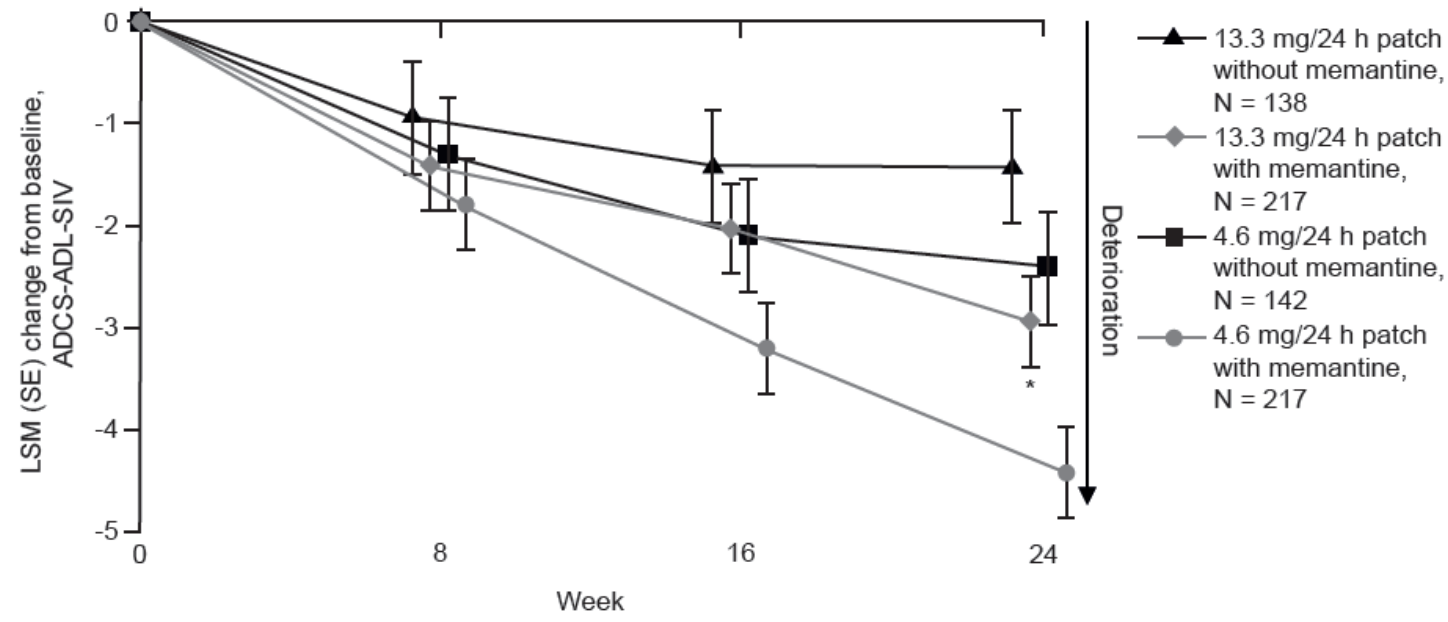

\begin{tabular}{|c|c|c|c|}
\hline \multicolumn{2}{|c|}{$\begin{array}{c}\text { Comparison } \\
(+, \text { with memantine; -, without memantine) }\end{array}$} & $\begin{array}{c}\text { Point estimate } \\
\text { (difference LSM, Week 24) }\end{array}$ & P-value \\
\hline $13.3 \mathrm{mg} / 24 \mathrm{~h} \mathrm{-}$ & $13.3 \mathrm{mg} / 24 \mathrm{~h}+$ & 1.47 & 0.09 \\
\hline $13.3 \mathrm{mg} / 24 \mathrm{~h}-$ & $4.6 \mathrm{mg} / 24 \mathrm{~h}-$ & 0.97 & 0.27 \\
\hline $13.3 \mathrm{mg} / 24 \mathrm{~h}-$ & $4.6 \mathrm{mg} / 24 \mathrm{~h}+$ & 2.91 & 0.0007 \\
\hline $13.3 \mathrm{mg} / 24 \mathrm{~h}+$ & $4.6 \mathrm{mg} / 24 \mathrm{~h} \mathrm{-}$ & -0.49 & 0.56 \\
\hline $13.3 \mathrm{mg} / 24 \mathrm{~h}+$ & $4.6 \mathrm{mg} / 24 \mathrm{~h}+$ & 1.44 & 0.04 \\
\hline $4.6 \mathrm{mg} / 24 \mathrm{~h}-$ & $4.6 \mathrm{mg} / 24 \mathrm{~h}+$ & 1.93 & 0.02 \\
\hline
\end{tabular}

ADCS-ADL-SIV, Alzheimer's Disease Cooperative Study-Activities of Daily Living scale-Severe Impairment Version; LSM, least-squares means; MFAS-LOCF, Modified Full Analysis Set with a Last Observation Carried Forward imputation; SE, standard error. Error bars represent the SE of the LSM. ${ }^{*} \mathrm{p}<0.0513 .3 \mathrm{mg} / 24$ h versus $4.6 \mathrm{mg} / 24 \mathrm{~h}$ rivastigmine patch. $13.3 \mathrm{mg} / 24 \mathrm{~h}$ patch without memantine, $\mathrm{n}=122 ; 13.3 \mathrm{mg} / 24 \mathrm{~h}$ patch with memantine, $\mathrm{n}=186-188 ; 4.6 \mathrm{mg} / 24 \mathrm{~h}$ patch without memantine, $\mathrm{n}=119-121 ; 4.6 \mathrm{mg} / 24 \mathrm{~h}$ patch with memantine, $\mathrm{n}=181-182$. Change from baseline at Weeks 8, 16 and 24 shown (data points are staggered). 


\section{References}

[1] Exelon $^{\circledR}$ US prescribing information. 2006; Available from:

http://www.accessdata.fda.gov/drugsatfda_docs/label/2006/020823s016,021025s008lbl.pdf. (Accessed 24th October 2014).

[2] Exelon Patch ${ }^{\circledR}$ US Prescribing Information. 2009. Revised 2012 and 2013; Available from:

http://www.pharma.us.novartis.com/product/pi/pdf/exelonpatch.pdf (Accessed 24th October 2014).

[3] Aricept Prescribing Information. 2010; Available from:

http://www.aricept.com/docs/pdf/aricept_PI.pdf (Accessed 24th October 2014).

[4] Galantamine (Razadyne ER $^{\circledR}$ and Razadyne ${ }^{\circledR}$ ) Prescribing Information. 2005; Available from: http://www.razadyneer.com/sites/default/files/shared/pi/razadyne_er.pdf\#zoom=100 (Accessed 24th October 2014).

[5] Namenda US Prescribing Information. 2011; Available from: http://www.frx.com/pi/namenda_pi.pdf (Accessed 24 ${ }^{\text {th }}$ October 2014).

[6] Farrimond LE, Roberts E, McShane R. Memantine and cholinesterase inhibitor combination therapy for Alzheimer's disease: a systematic review. BMJ Open 2(3): pii: e000917 (2012).

[7] Tariot PN, Farlow MR, Grossberg GT, Graham SM, McDonald S, Gergel I. Memantine treatment in patients with moderate to severe Alzheimer disease already receiving donepezil: a randomized controlled trial. JAMA 291(3): 317-324 (2004).

[8] Porsteinsson AP, Grossberg GT, Mintzer J, Olin JT. Memantine treatment in patients with mild to moderate Alzheimer's disease already receiving a cholinesterase inhibitor: a randomized, double-blind, placebocontrolled trial. Curr Alzheimer Res 5(1): 83-89 (2008).

[9] Atri A, Molinuevo JL, Lemming O, Wirth Y, Pulte I, Wilkinson D. Memantine in patients with Alzheimer's disease receiving donepezil: new analyses of efficacy and safety for combination therapy. Alzheimer's Res Ther 5(1): 6 (2013).

[10] Howard R, McShane R, Lindesay J, Ritchie C, Baldwin A, Barber R, et al. Donepezil and memantine for moderate-to-severe Alzheimer's disease. N Engl J Med 366(10): 893-903 (2012).

[11] Doody RS, Geldmacher DS, Farlow MR, Sun Y, Moline M, Mackell J. Efficacy and safety of donepezil $23 \mathrm{mg}$ versus donepezil $10 \mathrm{mg}$ for moderate-to-severe Alzheimer's disease: a subgroup analysis in patients already taking or not taking concomitant memantine. Dement Geriatr Cogn Disord 33(2-3): 164-173 (2012)

[12] Farlow MR, Grossberg G, Gauthier S, Meng X, Olin JT. The ACTION study: methodology of a trial to evaluate safety and efficacy of a higher dose rivastigmine transdermal patch in severe Alzheimer's disease. Curr Med Res Opin 26(10): 2441-2447 (2010).

[13] Farlow MR, Grossberg GT, Sadowsky CH, Meng X, Somogyi M. A 24-week, randomized, controlled trial of rivastigmine patch $13.3 \mathrm{mg} / 24 \mathrm{~h}$ versus $4.6 \mathrm{mg} / 24 \mathrm{~h}$ in severe Alzheimer’s dementia. CNS Neurosci Ther 19(10): 745-752 (2013)

[14] McKhann G, Drachman D, Folstein M, Katzman R, Price D, Stadlan EM. Clinical diagnosis of Alzheimer disease: Report of the NINCDS-ADRDA Work Group under the auspices of Department of Health and Human Services Task Force on Alzheimer's disease. Neurology 34: 939-944 (1984). 
[15] Folstein MF, Folstein SE, McHugh PR. "Mini-mental state". A practical method for grading the cognitive state of patients for the clinician. J Psychiatr Res 12(3): 189-198 (1975).

[16] Saxton J, McGonigle-Gibson K, Swihart A, Miller M, Boller F. Assessment of the severely impaired patient: description and validation of a new neuropsychological test battery. Psychol Assess 2: 298-303 (1990).

[17] Galasko D, Bennett D, Sano M, Ernesto C, Thomas R, Grundman M, et al. An inventory to assess activities of daily living for clinical trials in Alzheimer's disease. The Alzheimer's Disease Cooperative Study. Alzheimer Dis Assoc Disord 11 Suppl 2: S33-39 (1997).

[18] Jann MW, Shirley KL, Small GW. Clinical pharmacokinetics and pharmacodynamics of cholinesterase inhibitors. Clin Pharmacokinet 41(10): 719-739 (2002).

[19] Bailey JA, Lahiri DK. A novel effect of rivastigmine on pre-synaptic proteins and neuronal viability in a neurodegeneration model of fetal rat primary cortical cultures and its implication in Alzheimer's disease. $\mathrm{J}$ Neurochem 112(4): 843-853 (2010).

[20] Bailey JA, Ray B, Greig NH, Lahiri DK. Rivastigmine lowers Abeta and increases sAPPalpha levels, which parallel elevated synaptic markers and metabolic activity in degenerating primary rat neurons. PLoS One 6(7): e21954 (2011).

[21] Anand R, Messina J, Hartman R. Dose-response effect of rivastigmine in the treatment of Alzheimer's disease. Int J Geriatr Psychopharmacol 2: 68-72 (2000).

[22] Davis KL, Mohs RC, Marin D, Purohit DP, Perl DP, Lantz M, et al. Cholinergic markers in elderly patients with early signs of Alzheimer disease. JAMA 281(15): 1401-1406 (1999).

[23] Winblad B, Cummings J, Andreasen N, Grossberg G, Onofrj M, Sadowsky C, et al. A six-month double-blind, randomized, placebo-controlled study of a transdermal patch in Alzheimer's disease - rivastigmine patch versus capsule. Int J Geriatr Psychiatry 22(5): 456-467 (2007).

[24] Choi SH, Park KW, Na DL, Han HJ, Kim EJ, Shim YS, et al. Tolerability and efficacy of memantine add-on therapy to rivastigmine transdermal patches in mild to moderate Alzheimer's disease: a multicenter, randomized, open-label, parallel-group study. Curr Med Res Opin 27(7): 1375-1383 (2011).

[25] Farlow MR, Alva G, Meng X, Olin JT. A 25-week, open-label trial investigating rivastigmine transdermal patches with concomitant memantine in mild-to-moderate Alzheimer's disease: a post hoc analysis. Curr Med Res Opin 26(2): 263-269 (2010).

[26] Winslow BT, Onysko MK, Stob CM, Hazlewood KA. Treatment of Alzheimer disease. Am Fam Physician 83(12): 1403-1412 (2011). 


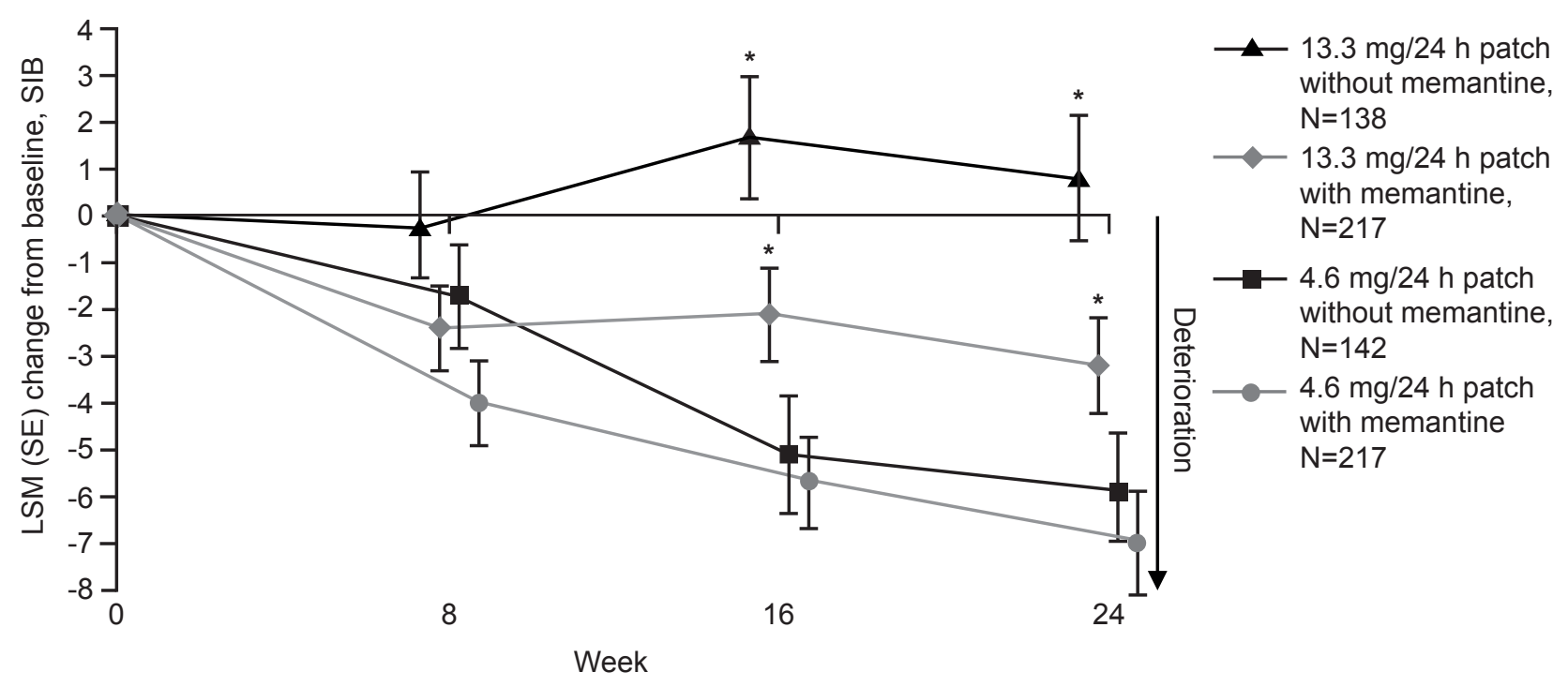




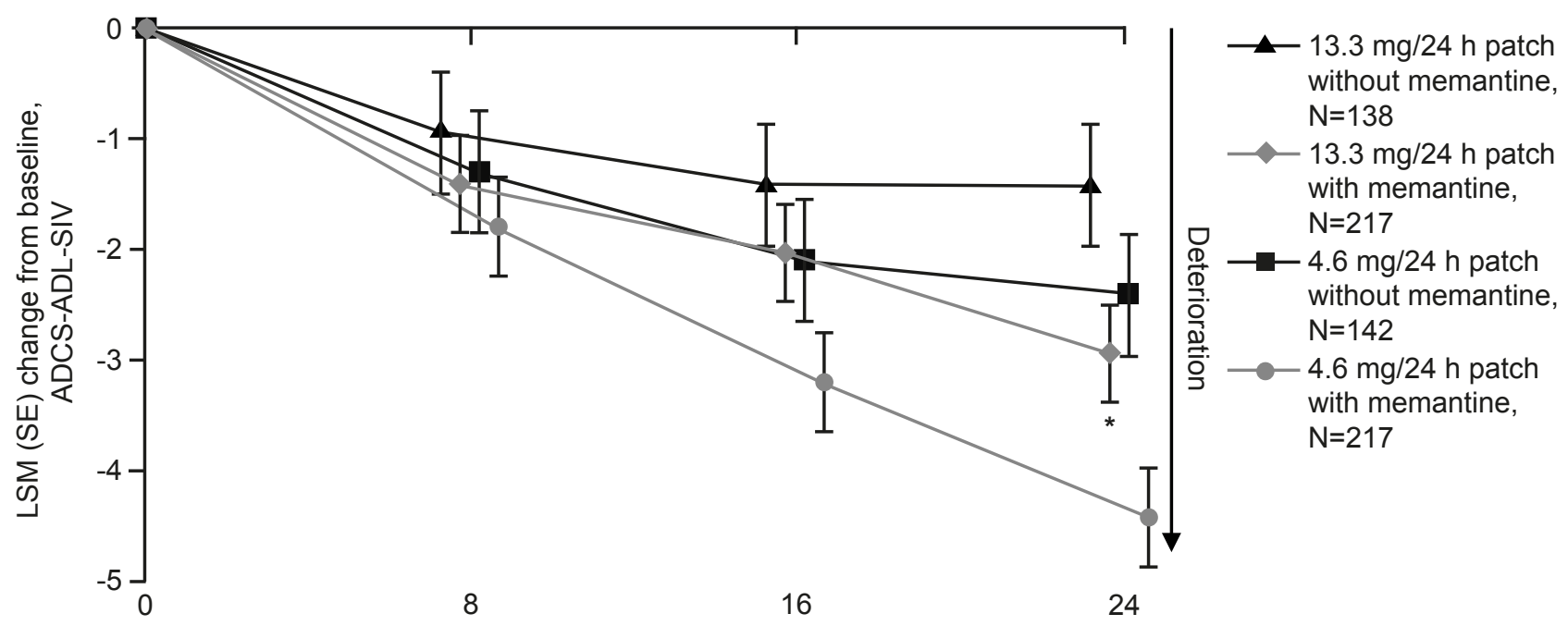

Week 